\title{
Abordagem Integradora para Implementação de um Sistema de Gestão de Segurança e Impactos de Visitação em Áreas Naturais Protegidas
}

\author{
Victor Lopez-Richard ${ }^{\mathrm{a}}$ \\ Andréia Márcia Cassiano ${ }^{b}$ \\ Rodrigo Jose Silva Aguiar
}

\section{Resumo}

A gestão de visitação em áreas protegidas age em duas frentes, em geral desconexas: a social e a biofísica. Na prática, a dicotomia entre gestão de segurança e de impactos da visitação transparece no uso de ferramentas díspares que inibe uma ou outra de acordo com a visão e capacitação das equipes envolvidas. Este trabalho propõe sistematizar uma visão integradora onde a qualidade da experiência da visitação, do ponto de vista da segurança da atividade, e as alterações ambientais diretas ou indiretas subsequentes possam ser ponderadas, avaliadas e geridas simultaneamente dentro de um Sistema de Gestão de Segurança e Impactos.

Palavras-Chave: Unidades de conservação; Ecoturismo; Sustentabilidade ambiental; Gestão de riscos.

\section{Abstract \\ An integrative approach for the implementation of a management system for safety and impacts of visitation in protected natural areas.}

The management of visitation in protected areas acts on two fronts, in general, disconnected: social and biophysical. In practice, the dichotomy between impact and safety managements, using disparate tools, inhibits one or another tool according to the vision and capacity of the management teams. This work aims to systematize an integrative vision where the quality of the visitation experience and the subsequent direct or indirect environmental changes can be weighted, evaluated and managed simultaneously within a Security and Impact Management System.

Keywords: Conservation areas; Ecotourism; Environmental sustainability; Risk management.

a. Doutor em Ciências pela Universidade Federal de São Carlos, São Carlos, São Paulo, Brasil. Docente no curso de Física e no Programa de Extensão Gestão e Promoção de Atividades na Natureza e Áreas Protegidas na Universidade Federal de São Carlos, São Carlos, São Paulo, Brasil. E-mail: vlopez@df.ufscar.br.

b. Doutora em Ciências da Engenharia Ambiental pela Universidade de São Paulo, São Carlos, São Paulo, Brasil. Docente no curso de Gestão Ambiental da FATEC Nilo de Stéfani, Jaboticabal, São Paulo, Brasil. E-mail: andreiacassiano@yahoo.com.br.

c. Tecnólogo em Gestão Ambiental Agroflorestal pela Faculdade de Tecnologia do Vale do Ribeira, Registro, São Paulo, Brasil. Especialista em Emergências Ambientais. Gestor da Área de Proteção Ambiental - Quilombos do Médio Ribeira. E-mail: raguiar01@hotmail.com. 


\section{Resumen}

Enfoque integrador para implementar un sistema de gestión de seguridad e impactos de visitas en áreas naturales protegidas.

La gestión de visitas en áreas protegidas actúa en dos frentes, generalmente desconectados: el social y el biofísico. En la práctica, la dicotomía entre la gestión de seguridad y los impactos de las visitas se refleja en el uso de herramientas dispares que inhiben una u otra según la visión y formación de los equipos implicados. Este trabajo propone sistematizar una visión integradora donde la calidad de la experiencia de visita, desde el punto de vista de la seguridad de la actividad, y los posteriores cambios ambientales directos o indirectos puedan ser considerados, evaluados y gestionados simultáneamente dentro de un Sistema de Gestión de Seguridad e Impactos.

Palabras Claves: Unidades de conservación; Ecoturismo; Sostenibilidad ambiental: Gestión de riesgos.

\section{INTRODUÇÃo}

0 turismo em áreas naturais protegidas tem sido considerado uma atividade com potencial para a promoção do desenvolvimento econômico e social, visto que além de permitir a proteção de ecossistemas pode promover desenvolvimento econômico inclusivo (Nyaupane \& Poudel, 2011; Lobo, 2015). Frente a isto, surgem desafios dentre os quais a implementação de ferramentas para minimizar, mitigar e monitorar os impactos da visitação e a inserção de mecanismos de gestão de riscos relacionados à segurança das atividades turísticas desenvolvidas.

No Brasil, a estruturação do Sistema Nacional de Unidades de Conservação (SNUC) pela Lei Federal n 9.985/2000 (Brasil, 2000) veio ordenar vários institutos relacionados à conservação e preservação de áreas naturais incluindo o estabelecimento de tipos de Unidades de Conservação (UCs), usos possíveis, bem como instrumentos de gestão destas áreas. Assim, as UCs que tem dentre seus objetivos a visitação pública surgem como espaços de interesse para o desenvolvimento de atividades de ecoturismo. Nesse contexto, a gestão de visitação está sujeita a administrar dois paradoxos: (i) a exploração do caráter pristino do ambiente como atrativo turístico e os inevitáveis impactos decorrentes que podem afetar este mesmo valor ao estressar os recursos naturais (Garrod \& Fyal, 1998; Williams \& Ponsfor, 2009) e (ii) os riscos inerentes à execução de atividades de lazer em ambientes naturais (Cater, 2006). Prover padrões de precaução idôneos (Lopez-Richard, Alamino \& Simões, 2007) é um imperativo para a indústria de turismo e também resulta num princípio básico da gestão do uso público de áreas protegidas como destinos de visitação e lazer (Bentley \& Page, 2001; Bentley \& Page, 2008).

Ainda que existam no Brasil iniciativas governamentais relacionadas à gestão de impactos de visitação e de gestão de riscos em áreas protegidas, detalhadas a seguir no marco teórico, estas, muitas vezes, encontram-se desarticuladas entre si, centralizadas pelo órgão gestor e carentes de recursos e pessoal para sua adequada implementação, e constata-se um conflito entre prioridades e ferramentas de gestão díspares. Visões políticas e técnicas conflitantes também se interpõem como obstáculos para a execução harmônica destas frentes, por vezes, sendo priorizada uma ou outra forma de gestão. 
Em parte, considera-se que essas visões de gestão conflitantes e mesmo antagônicos tem relação à dicotomia entre os conceitos de ecoturismo e turismo de aventura, uma vez que os mesmos norteiam a construção de distintas ferramentas de gestão da visitação de áreas naturais. Assim, no primeiro caso são privilegiadas ferramentas de gestão do impacto da visitação sobre o ambiente biofísico e, no segundo, de gestão de risco à segurança dos participantes nessas atividades.

Partindo dessa problemática e da hipótese da possível integração e complementariedade entre essas ferramentas, o presente trabalho busca discutir esses conceitos e como suas interpretações tem norteado a construção das formas de gestão da visitação de áreas naturais protegidas. Este trabalho irá explorar como a aparente dicotomia entre os conceitos de ecoturismo e turismo de aventura afeta o caráter ontológico da maneira como são interpretados ao usá-los como definições norteadoras na construção de ferramentas de gestão de visitação de áreas naturais protegidas. Adicionalmente indicará que, do ponto de vista epistemológico estes conceitos são complementares, e do ponto de vista prático demonstrará ser possível a estruturação de sistemas de gestão capazes de integrar metodologicamente a gestão de impactos da visitação e os riscos à segurança relacionados a estas atividades.

Do ponto de vista prático e metodológico, destaca-se a proposta de abordagem integradora da estruturação de um sistema de gestão de segurança e impactos de visitação em áreas naturais protegidas, que constitui o objeto principal do presente trabalho. Este processo pode ser compreendido como um contínuo de implementação, avaliação e correção seguindo um ciclo PDCA ou ciclo Deming (Reid et al., 1999) que permite à gestão se adaptar com facilidade a novas informações e situações (McCool \& Cole 1997).

\section{OBJETIVOS}

0 presente trabalho tem como objetivos, primeiramente, discutir conflitos entre conceitos e metodologias norteadoras para processos de gestão da visitação em áreas naturais protegidas. Subsequentemente, apresentar uma proposta de integração sistemática de métodos, atualmente desconexos, quais sejam: (a) aqueles voltados à qualidade da experiência da visitação em termos de segurança; e, (b) aqueles relacionados ao manejo das alterações no ambiente induzidas pela atividade, direta ou indiretamente. Assim, as discussões apresentadas irão qualificar fragilidades identificadas em diagnósticos de gestão de visitação em UCs orientando a estruturação de maneira efetiva de um Sistema de Gestão de Segurança e Impactos da visitação (SGSI).

Será proposta uma ferramenta integradora destas frentes que facilite sua implementação. Do ponto de vista metodológico, este SGSI se estrutura entorno de uma ferramenta que integra a avaliação e gestão dos Limites Aceitáveis de Câmbios (LAC) (Stankey et al, 1985) com os Limites Aceitáveis de Riscos (LAR) (ABNT, 2014). Desta maneira, coloca no mesmo nível de priorização e dentro de um único marco metodológico as condições aceitáveis de impactos e de riscos para a visitação.

Esta metodologia, que será denominada no presente trabalho de LAR+LAC, se propõe explicitar a definição de indicadores quantitativos e qualitativos simultâneos para ambas dimensões, assim como mecanismos de monitoramento 
sistemático e revisões subsequentes, caso necessário, utilizando registros e processos facilmente auditáveis. Também permite executar estas frentes dentro das restrições que o zoneamento impõe à visitação em UCs nos seus Planos de Manejo. Outrossim, ao destacar as vantagens de uma possível gestão compartilhada com gestores, monitores, condutores e usuários; a visitação é reavaliada como oportunidade simbiótica com a gestão e não somente como potencial vetor de pressão e fonte de preocupações (Weaver \& Lawton, 2017).

\section{MARCO TEÓRICO}

Preliminarmente devem-se contextualizar os conceitos de ecoturismo e turismo de aventura e a maneira como os mesmos apontam, à primeira vista, para dimensões díspares: a sustentabilidade socioambiental no primeiro e os riscos à integridade dos envolvidos, no segundo. A EMBRATUR, Instituto Brasileiro de Turismo vinculado ao Ministério de Turismo, define ecoturismo como (EMBRATUR, 1994): "segmento da atividade turística que utiliza, de forma sustentável, o patrimônio natural e cultural, incentiva sua conservação e busca a formação de uma consciência ambientalista por meio da interpretação do ambiente, promovendo o bem-estar das populações envolvidas".

Segundo o Ministério do Turismo (2006), o turismo de aventura "compreende os movimentos turísticos decorrentes da prática de atividades de aventura de caráter recreativo e não competitivo" e estas, por sua vez, podem são definidas pela Associação Brasileira de Normas Técnicas (ABNT) (ABNT, 2019) como: "atividades para fins turísticos que envolvem um grau de instrução ou de liderança e um elemento de risco deliberadamente aceito". Entende-se aqui como risco a combinação de probabilidade com o grau de severidade dos potenciais danos (materiais, à integridade física, etc.) que possam eventualmente se concretizar (ABNT, 2014).

Ao discutir turismo de aventura, fatores de risco aparecem como elementos intrinsecamente motivadores para o envolvimento de pessoas em atividades de lazer na natureza (Lopez-Richard \& Chinaglia, 2004). Em contraste, no Manual de Ecoturismo: Orientações básicas do Ministério do Turismo (2010), o conceito de risco aparece vinculado exclusivamente à resposta a emergências e à prevenção de acidentes.

Mesmo que o conceito de risco não apareça explicitamente na definição de ecoturismo indicada acima, assim como o de sustentabilidade socioambiental não aparece explicitamente para o turismo de aventura, Bentley, Carter \& Page (2010) explicam que o envolvimento de clientes de ecoturismo em atividades em ambientes não familiares, onde se impõe seguir certas instruções mínimas, e sob condições com certo grau de incerteza, requer igualmente a gestão de segurança para manter os riscos em níveis aceitáveis. Concomitantemente, deve-se destacar que o conceito de sustentabilidade se inclui de maneira transversal em vários instrumentos normativos do turismo de aventura, seja como requisito para boas práticas (ABNT, 2019) ou na recomendação de conhecimentos sobre mínimo impacto aos seus líderes (ABNT, 2015). Diferentemente de versões prévias, a definição explicitada na Norma ABNT (2019) reconhece explicitamente que as atividades de aventura podem "usualmente incluir interação com o meio ambiente". 
Assim como nas definições aparentemente díspares descritas acima, as ferramentas de gestão que abordam sustentabilidade e segurança aparecem como dimensões separadas no receituário metodológico disponível: a biofísica (SMA, 2010) e a social (ABETA, 2009), respectivamente. Ambas dimensões são discutidas na literatura técnica (Williams \& Ponsfor, 2009; Williams \& Soutar, 2009). Nesse escopo cabe destacar o processo LAC introduzido em 1985 por Stankey et al. como balizador para estruturar sistemas de gestão de impactos de visitação em áreas naturais protegidas. De acordo com este conceito, as mudanças a serem permitidas ou não no ambiente são definidas por meio de indicadores quantitativos, cujo monitoramento deve sinalizar as ações de manejo necessárias para evitar mudanças indesejáveis.

Relacionado à gestão dos impactos da visitação, o Instituto Chico Mendes de Conservação da Biodiversidade (ICMBio), órgão Federal que executa as ações do SNUC, propôs um Roteiro Metodológico para Manejo de Impactos da Visitação (ICMBio, 2011). O mesmo consiste na determinação do Número Balizador da Visitação e seu ajuste a partir de revisões iterativas usando indicadores ambientais de impactos ou da alteração de fatores limitantes de manejo e inclui o LAC como umas das referências. Por sua vez, a Fundação Florestal do Estado de São Paulo elaborou um guia com propósitos semelhantes explicitado no Manual de Monitoramento e Gestão dos Impactos da Visitação em Unidades de Conservação (SMA, 2010). Por exemplo, o Plano de Manejo do Parque Estadual Carlos Botelho (SMA, 2008b) sugere também o LAC como ferramenta potencial a ser implementada em sua gestão. Já outros Planos de Manejo indicam a aplicação de metodologias alternativas, tais como o Visitor Impact Management (Farrell \& Marion, 2002), contemplada no Parque Estadual Intervales (SMA, 2008c), ou não apontam nenhuma especificamente, como no caso do Parque Estadual Serra do Mar (SMA, 2008a).

No Estado de São Paulo, a Resolução da Secretaria do Meio Ambiente (SMA) $n^{\circ} 59$ (SMA, 2008) explicita também a necessidade de monitoramento de impactos das atividades de uso público e no seu Artigo 13 indica o responsável pela sua execução como sendo a Fundação para a Conservação e a Produção Florestal do Estado de São Paulo, que "deverá monitorar as atividades de uso público nas Unidades de Conservação com vistas ao controle de impactos e eventual adequação das atividades". Por sua vez, a mesma Resolução SMA n 59 (SMA, 2008) regulamenta os procedimentos de gestão e administração das UCs e orienta que as mesmas devem contar com um Plano de Gestão de Riscos e Contingências indicando seu conteúdo mínimo. Estas diretrizes apontam a uma gestão de segurança reativa com foco na resposta a emergências semelhante ao indicado no Manual de Ecoturismo: Orientações básicas do Ministério do Turismo (2010).

Outra referência a respeito da gestão de riscos é a Norma da ABNT (2014) que propõe requisitos mínimos para a implementação de Sistemas de Gestão de Segurança (SGS) em atividades de Turismo de Aventura, mas que ainda não foi adequadamente apropriada de maneira orgânica pelas receitas de gestão das UCs brasileiras que tem programas de visitação pública. Nesta norma aparece o conceito de LAR como limiar de referência e define segurança como sendo o "estado em que o risco de dano ou lesão é limitado a um nível aceitável" indicando o que fazer para atingir estes níveis a partir do processo de identificação, análise, avaliação e tratamento destes riscos. 
A ferramenta proposta LAR+LAC busca contemplar simultaneamente ambas dimensões reconhecendo que as variáveis a quantificar, quais sejam a severidade de potenciais danos e suas probabilidades, são comuns tanto para riscos à segurança como para alterações ambientais.

\section{METODOLOGIA}

Esta pesquisa propõe uma abordagem qualitativa, de natureza aplicada (Silveira \& Córdova, 2009), com foco na caracterização da inter-relação dos diferentes atores e elementos que podem compor um possível SGSI. Dessa forma, foi efetuada uma revisão a respeito das metodologias existentes relativas à gestão de impactos de visitação e riscos à segurança em UCs, assim como uma pesquisa documental de Planos de Manejo das UCs, dentre aquelas atendidas pelo Programa de Extensão Universitária da Universidade Federal de São Carlos, intitulado Gestão e Promoção de Atividades na Natureza e Áreas Protegidas. Ademais, foram consultadas normas brasileiras e diretrizes relacionadas ao tema, principalmente aquelas produzidas pelo ICMBio e pela SMA do Estado de São Paulo. Os resultados deste trabalho, como pontua Yin (2001), foram objeto de uma generalização analítica a partir de discussões indutivas e análises críticas de marcos normativos previamente desenvolvidos, contra os quais experiências práticas foram contrastadas.

As vivências aconteceram dentro dos marcos do Programa de Extensão acima citado. Este, através do Projeto Capacitação e Treinamento para Gestão de Unidades de Conservação, tem focado, desde 2013, na estruturação de roteiros de visitação e na capacitação de Monitores Ambientais em UCs do Estado de São Paulo, quais sejam: Parque Estadual Serra do Mar, Parque Estadual Ilha Anchieta, Parque Estadual Turístico do Alto Ribeira, Parque Estadual Carlos Botelho e Parque Estadual Intervales. Cada ação do Projeto (executado entre 2013-2020) foi antecedida por diagnósticos envolvendo as equipes de gestão e as comunidades do entorno, a partir da aplicação de metodologia SWOT (Galvão de Sousa Dantas \& Sousa Melo, 2008).

Nestas vivências afloraram fragilidades, conflitos e oportunidades para a implementação de receitas metodológicas exigidas pelos próprios Planos de Manejo destas UCs, o que permitiu o debate entre equipes de Gestão e monitores ambientais e o subsequente aprimoramento e adaptação de ferramentas de gestão. A experiência também constatou que estes processos contemplam interesses e objetivos conflitantes, logo, ambientes de fato colaborativos são essenciais para levar adiante agendas em prol de metas de sustentabilidade para o sistema socioecológico em questão, tal como antecipado por McCool (2009).

\section{RESULTADOS E DISCUSSÕES}

Como descrito no Marco Teórico, um elemento que contribui para a falsa dicotomia entre a priorização da gestão de impactos e gestão da segurança da visitação é a visão ingênua, e incorreta, de que atividades de ecoturismo, com foco na apreciação e interpretação do ambiente com práticas sustentáveis do ponto 
de vista socioambiental, não classificam como aventura e não deveriam priorizar a gestão de riscos à segurança dos participantes. A falta explícita da menção a perigos e riscos na definição de atividades de ecoturismo e sua menção explícita no caso de turismo de aventura, tem levado a uma subestimação dos seus efeitos no primeiro caso e a incompreensões sobre sua valorização ou glamourização, no segundo. Simplificar também o risco à dimensão exclusiva da segurança dos praticantes da atividade não permite reconhecer seu papel como elemento motivador para a tomada de decisão do participante neste tipo de atividade. Como alerta Cater, (2006): "o risco sobre o qual os participantes falam pode estar divorciado daquele que os operadores precisam considerar e isso tem importantes implicações de gerenciamento para os operadores de aventura".

A partir das vivências nas citadas UCs, verificou-se a existência de carências na implementação efetiva de ferramentas de gestão para lidar, tanto com os impactos ambientais da visitação, quanto da segurança na condução destas atividades pelas equipes que lidam com o uso público. Este diagnóstico encontra-se resumido na matriz SWOT do Quadro 1.

Quadro 1 - Matriz SWOT dos processos de diagnósticos sobre a gestão da visitação em UCs no estado de São Paulo como parte do Programa Gestão e Promoção de Atividades na Natureza e Áreas Protegidas

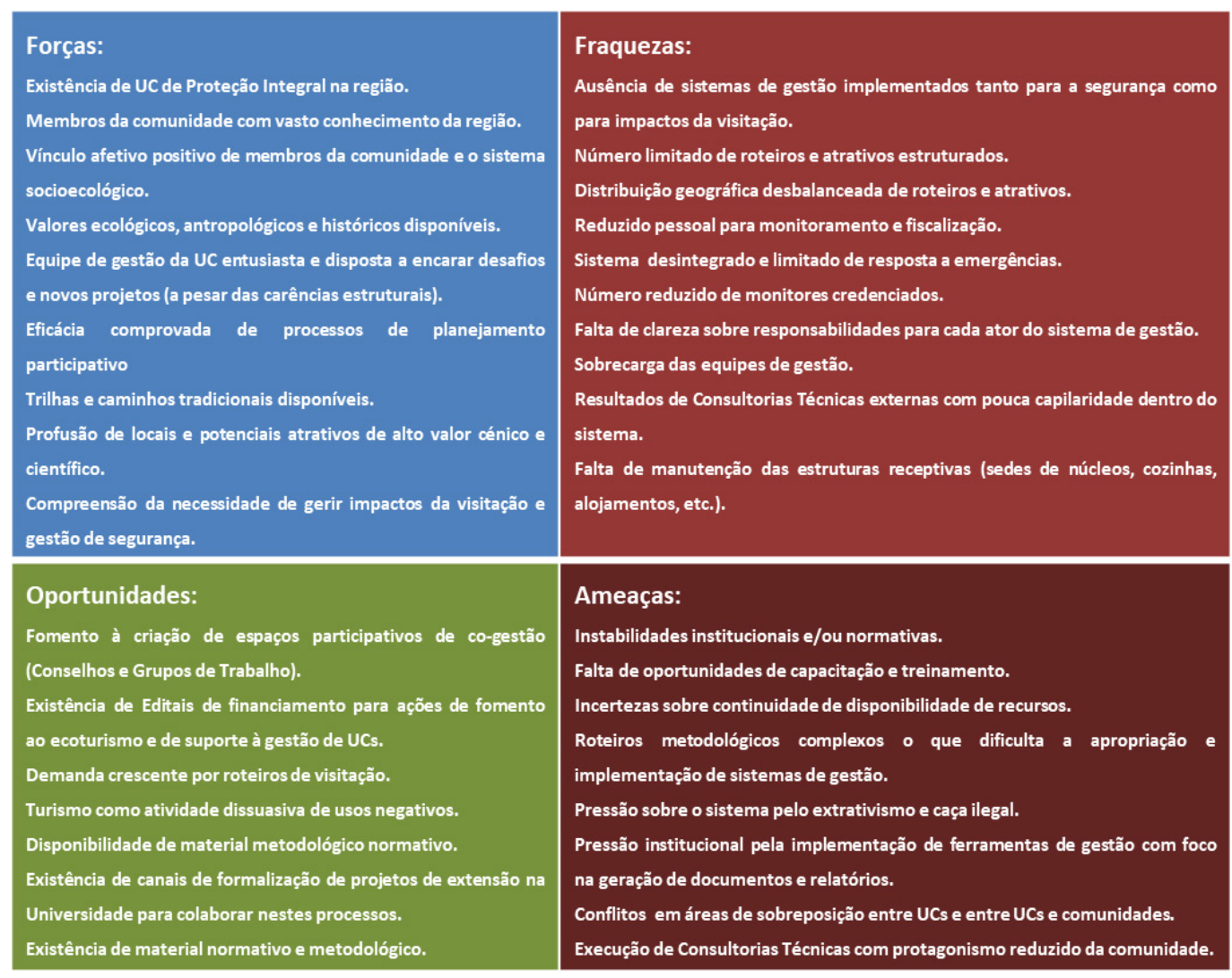

Fonte - dados da pesquisa.

Explicitado como fraqueza no Quadro 1, destaca-se a ausência de sistemas ativos e permanentes de avaliação e monitoramento, a não ser em situações graves de crise que requerem uma resposta reativa. Tampouco o limitado número de atores envolvidos diretamente com a gestão de uso público dispõe de 
ferramentas simplificadas e claras para executar adequadamente suas funções preventivas e fiscalizadoras a respeito. Mesmo as ações reativas são apenas corretivas, sem registros padronizados e avaliações sistemáticas posteriores da efetividade das medidas tomadas, características de sistemas de gestão considerados desejáveis (ABNT, 2014).

Consequências destas fragilidades são: i) gestão de segurança reduzida essencialmente a documentos que descrevem a resposta a emergências em vez de uma ocupação sistemática, de caráter fundamentalmente preventivo e não reativo; ii) capacitação técnica de equipes de gestão e condução com foco na interpretação e conhecimentos sobre o ambiente e pouca ênfase na gestão de segurança e as competências técnicas que a mesma exige (Cassiano et al., 2016); e, iii) a gestão de impactos de visitação reduzida à determinação de capacidade de carga ou manejo ou do número balizador da visitação de atrativos e roteiros, que não reconhece a dinâmica e complexidade destes fatores.

Como reforça o Roteiro Metodológico do ICMBio (2011), o grau de impacto não depende necessariamente da quantidade de visitantes, já que o comportamento destes pode ser o fator desencadeante de danos (Gossling, 2002) e isto vale também para a eventual concretização de riscos à segurança. Logo, o cálculo de um número balizador de visitação e seu uso como única ferramenta de gestão pode não ser a melhor opção de tratamento da questão, podendo este ser reduzido a uma referência formal, não vinculante para uma adequada avaliação de impactos e riscos.

Outra falha detectada é a falta de ponderação sistemática de situações de perigo que podem desencadear tanto riscos à integridade física de participantes e/ou equipamentos, assim como impactos ambientais induzidos a partir de pretensas ações com fins de minimizá-los como, por exemplo, implantação de estruturas para "segurança" sem um sistema de monitoramento periódico. Tais sistemas tendem a induzir no participante uma sensação de segurança capaz de fazer relaxar seus níveis de precaução se tornando, assim, fontes adicionais de riscos, caso não estejam contemplados dentro de um processo sistemático de checagens. Outrossim, fragilidades estruturais podem ser causadas pelo intemperismo e durabilidade finita dos materiais ou falhas de construção. Estes são fatores de risco, e até de impactos ambientais, no caso, por exemplo, de gerar desestabilizações de encostas, processos erosivos e/ou movimentos de massas. A modificação do ambiente para implantação de estruturas para visitação, com seus inevitáveis impactos, por sua vez, pode sim resultar necessária e justificada, sempre que realizada a partir de uma criteriosa análise de riscos e de impactos ambientais, devendo ser objeto de estudos, monitoramentos e auditorias sistemáticas críticas. Assim, entende-se que não há como dissociar fatores ambientais limitantes da visitação, de fatores de risco e tampouco é possível concordar com visões ingênuas do ecoturismo como atividade segura e ambientalmente neutra.

A proposta de integração da gestão de segurança e impactos da visitação em áreas naturais protegidas vale-se das vantagens indicadas como forças e oportunidades no Quadro 1 destacando a indicação normativa da necessidade de regulação de impactos da visitação e gestão de segurança. Para estruturá-la é necessário compreender que o ciclo de gestão de impactos da visitação e seus riscos deve ser concebido como processo dinâmico e contínuo, sob uma lógica de aprimoramentos constantes (Stankey et al, 1985), como ilustrado na Figura 1. Esta visão coincide também com o requisito de melhoria contínua para SGS, segundo a 
Norma ABNT (2014), baseado no ciclo PDCA (Reid et al 1999). Tal sistema deve ser entendido como um processo de gestão permanente e não como uma ferramenta eventual de resposta a crises.

Figura 1 - Melhoria contínua no processo LAR-LAC dentro do SGSI baseada num ciclo PDCA

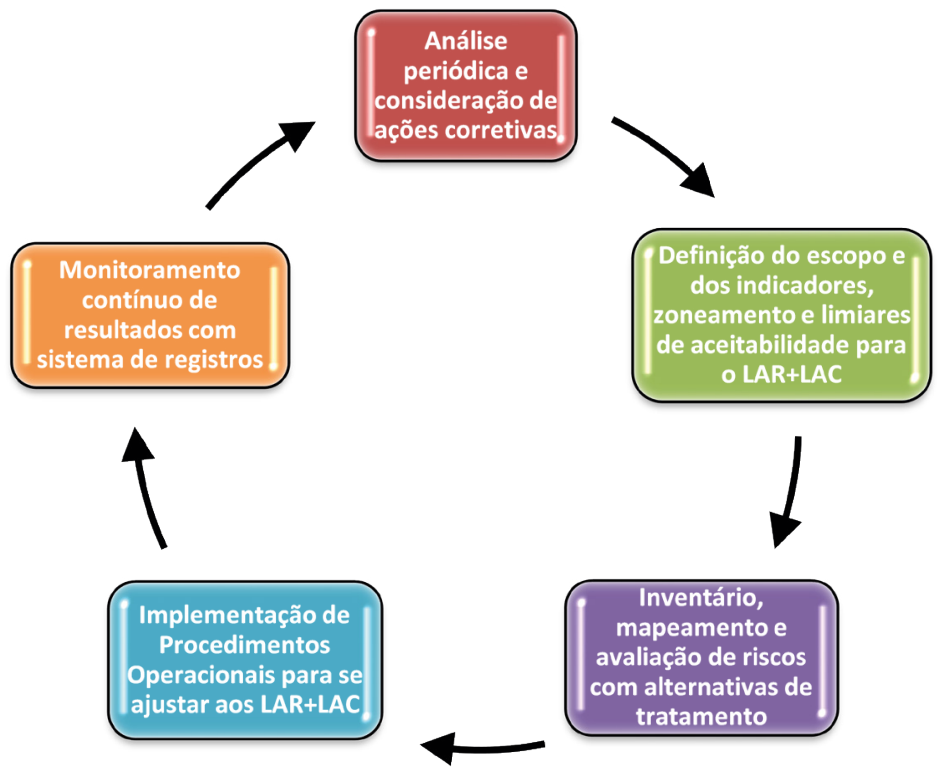

Fonte - Reid et al. 1999; ABNT, 2014.

O primeiro passo consiste na definição de metas objetivas a serem atingidas pela organização em relação à gestão de impactos e segurança e a indicação de como serão integrados os diferentes atores e recursos neste processo. Uma vez garantido o comprometimento destes, o escopo do SGSI poderá ser definido, cuja abrangência pode ser paulatinamente incrementada. Neste momento deverão se explicitadas as interfaces do sistema com o zoneamento da UC (ao qual estará subordinado), singularidades do meio físico e biótico (ressaltando tanto oportunidades como fragilidades), e questões antropológicas e sociais que ajudarão a ponderar a definição de indicadores, procedimentos de avaliação e limiares de aceitabilidade, tanto para riscos a participantes (terminologia que inclui também os condutores), como para alterações ao ambiente. Cabe destacar que os métodos e classificações de zoneamento de UCs sofreram adaptações entre as referências IBAMA (2002) e ICMBIO (2018) e continuam a ter um caráter normativo mais permanente; enquanto a setorização do SGSI acontece em escalas diferentes (de acordo com roteiros, atividades e/ou atrativos) e está sujeita a reavaliações e potenciais ações corretivas sistemáticas.

Para iniciar a avaliação LAR+LAC, as situações que podem levar a algum tipo de dano ou ameaça na atividade ou produto específico devem ser previamente listadas e, como todo registro do sistema, poderá sofrer alterações a partir de revisões subsequentes. 0 inventário preliminar deve ponderar e mapear os perigos ou fontes potenciais de riscos e danos dentro do escopo definido para o sistema, incluindo fatores humanos, organizacionais e ambientais. Uma vez listados poderão ser definidos indicadores que permitam tanto qualificar como quantificar os danos que 
serão eventualmente monitorados, tal como se exemplifica nos Quadros 2, 3 e 4 para ameaças ao ambiente, à segurança de participantes, e à qualidade da experiência dos envolvidos (incluindo as comunidades), respectivamente. Destaca-se que estes Quadros são ilustrativos e não exaustivos. Sendo o risco o resultado da combinação de probabilidade de se concretizar (P) com a severidade estimada do dano (S), estas dimensões deverão ser quantificadas numa escala numérica. Na Figura 2 foi utilizada uma escala de 1 a 5 para avaliar a probabilidade entre improvável $(=1)$ e quase certa $(=5)$, assim como para a severidade entre insignificante $(=1)$ e catastrófica (=5), respectivamente como sugerido na referência ABETA (2009).

Quadro 2 - Exemplos de fatores de atenção ambiental, potenciais danos qualificáveis ou quantificáveis resultantes e ações preventivas ou corretivas

\begin{tabular}{|c|c|c|}
\hline $\begin{array}{l}\text { Exemplos de fatores } \\
\text { de atenção ou de } \\
\text { vulnerabilidade ambiental }\end{array}$ & $\begin{array}{l}\text { Exemplos de potenciais } \\
\text { danos qualificáveis ou } \\
\text { quantificáveis }\end{array}$ & $\begin{array}{l}\text { Exemplos de potenciais ações } \\
\text { preventivas ou corretivas }\end{array}$ \\
\hline $\begin{array}{l}\text { Vestígios de passagem de } \\
\text { animais }\end{array}$ & Afugentamento de fauna & $\begin{array}{l}\text { Não interferir ou modificar de } \\
\text { qualquer forma tais passagens / } \\
\text { orientação prévia }\end{array}$ \\
\hline Nidificação & $\begin{array}{l}\text { Afugentamento de fauna / } \\
\text { extinção }\end{array}$ & $\begin{array}{l}\text { Evitar traçados de trilhas em } \\
\text { locais de nidificação / suspender } \\
\text { temporariamente a atividade no } \\
\text { local / ajustar a visitação a níveis } \\
\text { que reduzam a perturbação da } \\
\text { espécie no período de reprodução / } \\
\text { orientação prévia / sinalização }\end{array}$ \\
\hline Plantas raras e frágeis & Extração / extinção & $\begin{array}{l}\text { Isolamento do local / orientação } \\
\text { prévia, proibição } \\
\text { de atividade no local }\end{array}$ \\
\hline Espécies em risco & $\begin{array}{l}\text { Extração / extinção e } \\
\text { afugentamento }\end{array}$ & $\begin{array}{l}\text { Orientação prévia / isolamento } \\
\text { local / redução da intensidade de } \\
\text { visitação / proibição de atividade } \\
\text { no local }\end{array}$ \\
\hline Solo exposto em declive & $\begin{array}{l}\text { Erosão em sulcos, ravinas } \\
\text { ou voçorocas / novos } \\
\text { atalhos não planejados }\end{array}$ & $\begin{array}{l}\text { Recuperação da área / interdição } \\
\text { da área / implantação de } \\
\text { estruturas para contenção } \\
\text { de processos erosivos / } \\
\text { disciplinamento de trilhas e/ou } \\
\text { fluxos de águas das chuvas }\end{array}$ \\
\hline Áreas alagáveis & $\begin{array}{l}\text { Novos atalhos não } \\
\text { planejados / alargamento } \\
\text { de trilhas e erosão }\end{array}$ & $\begin{array}{l}\text { Mudança de traçado / drenagens / } \\
\text { construção de estruturas elevadas / } \\
\text { contenção de processos erosivos ou } \\
\text { fluxos de águas }\end{array}$ \\
\hline $\begin{array}{l}\text { Terrenos íngremes } \\
\text { (barrancos/paredões de } \\
\text { rochas) }\end{array}$ & $\begin{array}{l}\text { Erosão / movimentos de } \\
\text { massas de terras ou de } \\
\text { blocos de rochas / novos } \\
\text { atalhos não planejados }\end{array}$ & $\begin{array}{l}\text { Interdição da área / recuperação da } \\
\text { área / implantação de estruturas } \\
\text { para interromper processos erosivo } \\
\text { ou de massas instalados / } \\
\text { implantar medidas para cessar } \\
\text { processo desencadeado }\end{array}$ \\
\hline
\end{tabular}




\section{Quadro 2 - Continuação}

\begin{tabular}{|c|c|c|}
\hline $\begin{array}{l}\text { Exemplos de fatores } \\
\text { de atenção ou de } \\
\text { vulnerabilidade ambiental }\end{array}$ & $\begin{array}{l}\text { Exemplos de potenciais } \\
\text { danos qualificáveis ou } \\
\text { quantificáveis }\end{array}$ & $\begin{array}{l}\text { Exemplos de potenciais ações } \\
\text { preventivas ou corretivas }\end{array}$ \\
\hline $\begin{array}{l}\text { Erosão próxima a corpos } \\
\text { d'água }\end{array}$ & $\begin{array}{l}\text { Assoreamento / perda } \\
\text { da qualidade da água por } \\
\text { turbidez }\end{array}$ & $\begin{array}{l}\text { Recuperação da área fonte de } \\
\text { sedimentos / Recuperação da área / } \\
\text { interdição da área / implantação } \\
\text { de estruturas para contenção de } \\
\text { processos erosivos / } \\
\text { disciplinamento de trilhas e/ou } \\
\text { fluxos de águas das chuvas }\end{array}$ \\
\hline Vestígios de fogueiras & $\begin{array}{l}\text { Solo exposto / incêndio } \\
\text { / esterilização de solo / } \\
\text { afugentamento de fauna / } \\
\text { perda de vegetação }\end{array}$ & $\begin{array}{l}\text { Orientação prévia / proibição } \\
\text { de fogueiras / demarcação de } \\
\text { área específica para preparo } \\
\text { de alimentação }\end{array}$ \\
\hline Pisoteio de vegetação & $\begin{array}{l}\text { Solo exposto / erosão } \\
\text { / danos à vegetação / } \\
\text { alargamento de trilhas }\end{array}$ & $\begin{array}{l}\text { Isolamento da área / delimitação } \\
\text { da trilha / orientação prévia }\end{array}$ \\
\hline Atalhos em trilhas & $\begin{array}{l}\text { Solo exposto / erosão / } \\
\text { danos à vegetação }\end{array}$ & $\begin{array}{l}\text { Redesenho do caminhamento / } \\
\text { isolamento do atalho / sinalização } \\
\text { indicativa de percurso }\end{array}$ \\
\hline Espeleotemas frágeis & Destruição & $\begin{array}{l}\text { Informação prévia / isolamento } \\
\text { de áreas com maior grau de } \\
\text { fragilidade / obrigatoriedade de } \\
\text { acompanhamento de condutor } \\
\text { ambiental cadastrado na UC }\end{array}$ \\
\hline Despejo de resíduos & $\begin{array}{l}\text { Degradação da paisagem } \\
\text { por presença de lixo / } \\
\text { contaminação dos solos e } \\
\text { águas / atração de fauna } \\
\text { e vetores }\end{array}$ & $\begin{array}{l}\text { Orientação prévia / instalação de } \\
\text { locais adequados para despejo } \\
\text { de resíduos com sistema de } \\
\text { tratamento }\end{array}$ \\
\hline Fezes & $\begin{array}{l}\text { Degradação da qualidade } \\
\text { dos solos e águas / } \\
\text { degradação das áreas de } \\
\text { descanso e acampamento }\end{array}$ & $\begin{array}{l}\text { Orientação prévia / instalação de } \\
\text { locais adequados para despejo } \\
\text { de resíduos com sistema de } \\
\text { tratamento / obrigatoriedade de } \\
\text { retornar com fezes para despejar } \\
\text { em locais apropriado / uso de } \\
\text { tecnologias para neutralizar fezes }\end{array}$ \\
\hline Material malacológico & $\begin{array}{l}\text { Extração de conchas / } \\
\text { fragilização da fauna }\end{array}$ & $\begin{array}{l}\text { Orientação prévia / isolamento da } \\
\text { área / sinalização / desvio de trilha }\end{array}$ \\
\hline
\end{tabular}

Fonte - dados da pesquisa. 
Quadro 3 - Exemplos de perigos ao participante, potenciais danos qualificáveis ou quantificáveis resultantes e ações preventivas ou corretivas

\begin{tabular}{|c|c|c|}
\hline $\begin{array}{l}\text { Exemplos de perigos para } \\
\text { o participante }\end{array}$ & $\begin{array}{l}\text { Exemplos de potenciais } \\
\text { danos qualificáveis ou } \\
\text { quantificáveis }\end{array}$ & $\begin{array}{l}\text { Exemplos de potenciais ações } \\
\text { preventivas ou corretivas }\end{array}$ \\
\hline Trechos escorregadios & Entorse / fratura & $\begin{array}{l}\text { Orientação preliminar / suporte } \\
\text { ativo no local / corrimão }\end{array}$ \\
\hline $\begin{array}{l}\text { Trecho de exposição ao } \\
\text { sol forte }\end{array}$ & Insolação / desidratação & $\begin{array}{l}\text { Orientação preliminar / } \\
\text { recomendação de uso de protetor } \\
\text { solar e vestimenta adequada }\end{array}$ \\
\hline Corpo molhado por chuva & Hipotermia & $\begin{array}{l}\text { Orientação preliminar / } \\
\text { kit de emergência }\end{array}$ \\
\hline $\begin{array}{l}\text { Quedas em desníveis } \\
\text { abruptos }\end{array}$ & $\begin{array}{l}\text { Entorse / escoriação / } \\
\text { fratura / traumatismo } \\
\text { craniano }\end{array}$ & $\begin{array}{l}\text { Orientação preliminar/ suporte } \\
\text { ativo no local / corrimão }\end{array}$ \\
\hline Quedas da própria altura & Entorse / escoriação & $\begin{array}{l}\text { Orientação preliminar / suporte } \\
\text { ativo no local }\end{array}$ \\
\hline $\begin{array}{l}\text { Ataque de animais } \\
\text { peçonhentos }\end{array}$ & $\begin{array}{l}\text { Envenenamento, choque } \\
\text { anafilático }\end{array}$ & $\begin{array}{l}\text { Orientação preliminar / desvios / } \\
\text { uso de perneira / preenchimento } \\
\text { de fichas médicas }\end{array}$ \\
\hline Galhos cortantes e espinhos & Perfuração / arranhão & $\begin{array}{l}\text { Orientação preliminar / suporte } \\
\text { ativo no local }\end{array}$ \\
\hline $\begin{array}{l}\text { Insubordinação do } \\
\text { participante }\end{array}$ & Perda & Registros / orientação preliminar \\
\hline Queda na água & Afogamento & Uso de salva-vidas \\
\hline $\begin{array}{l}\text { Teto baixo e espeleotemas } \\
\text { no caminhamento }\end{array}$ & Escoriação & $\begin{array}{l}\text { Uso de capacete / orientação } \\
\text { preliminar }\end{array}$ \\
\hline
\end{tabular}

Fonte - dados da pesquisa.

Quadro 4 - Exemplos fatores sociais qualificáveis ou quantificáveis que podem afetar a qualidade da experiência dos envolvidos e ações preventivas ou corretivas

\begin{tabular}{|l|l|l|}
\hline $\begin{array}{l}\text { Exemplos de ameaças para } \\
\text { a qualidade da experiência } \\
\text { dos envolvidos }\end{array}$ & $\begin{array}{l}\text { Exemplos de potenciais } \\
\text { indicadores qualificáveis } \\
\text { ou quantificáveis }\end{array}$ & $\begin{array}{l}\text { Exemplos de potenciais ações } \\
\text { preventivas ou corretivas }\end{array}$ \\
\hline $\begin{array}{l}\text { Interferências entre grupos } \\
\text { no roteiro }\end{array}$ & $\begin{array}{l}\text { Número de encontros } \\
\text { indesejados }\end{array}$ & $\begin{array}{l}\text { Determinação de limites } \\
\text { para tamanhos de grupos / } \\
\text { estabelecimento de horários }\end{array}$ \\
\hline $\begin{array}{l}\text { Superlotação de local de } \\
\text { acampamento }\end{array}$ & Número de barracas & $\begin{array}{l}\text { Determinação de número } \\
\text { balizador de barracas no } \\
\text { acampamento }\end{array}$ \\
\hline $\begin{array}{l}\text { Limpeza de instalações e } \\
\text { trilhas }\end{array}$ & Reclamações & $\begin{array}{l}\text { Implementação de mutirões } \\
\text { e ações de monitoramento }\end{array}$ \\
\hline permanente
\end{tabular}

Fonte - dados da pesquisa. 
A Figura 2 ilustra graficamente a metodologia genérica de avaliação de riscos (ABNT, 2014), cujo nível é dado pelo produto de P e S. Este procedimento possibilitará definir uma escala de tratamentos a partir de um Limiar de Aceitabilidade para níveis de risco que deverá ser acertado de maneira consensual dentro da equipe de planejamento. Esta escala permite a indicação de evitar certos tipos de risco ou a orientação de tratamentos para alterar, seja a probabilidade ou a severidade de cada dano previsto, a partir da implementação de procedimentos operacionais adequados. Aqueles riscos avaliados abaixo do limiar de aceitabilidade não precisarão de tratamento. A experiência sugere reavaliar o valor e, portanto, eficácia deste limiar nos primeiros ciclos iterativos (aproximações sucessivas) de revisão do sistema, sendo este limiar a meta do processo LAR+LAC (Cole \& Stankey, 1997).

Figura 2 - Metodologia de avaliação de riscos e de definição do limiar de aceitabilidade LAR+LAC

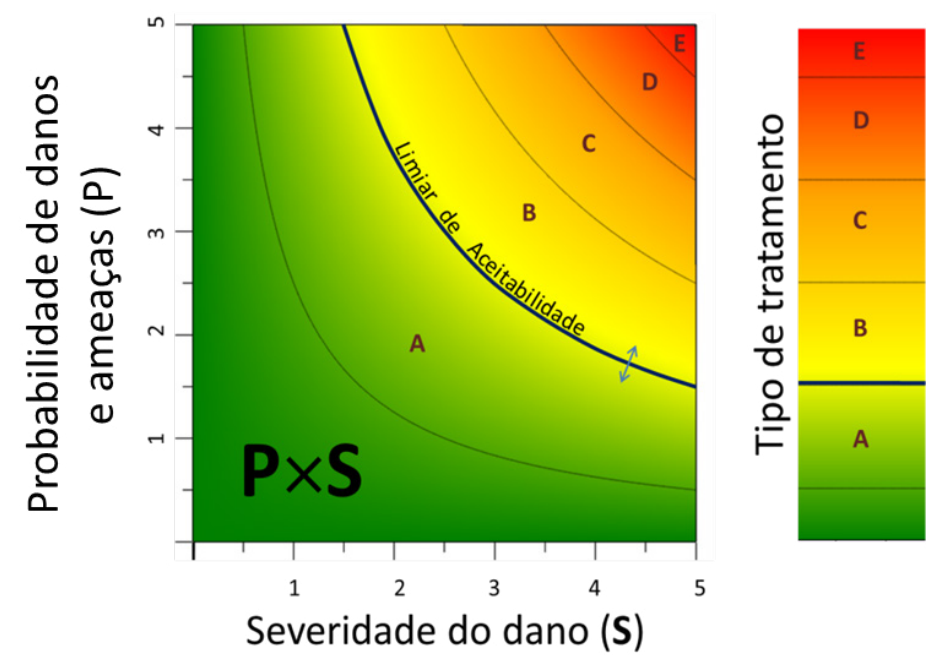

Fonte - Dados da pesquisa.

Não existe um valor padrão para o Limiar de Aceitabilidade, que deverá ser construído a partir do bom senso e experiência da equipe de planejamento. Mesmo podendo estar sujeito a correções, sendo um padrão quantitativo balizador do processo, é salutar para o sistema de gestão a estabilidade deste parâmetro. A calibragem adequada do Limiar de Aceitabilidade pode ser facilitada por duas vias descritas a continuação. Não é incomum que processos de gestão de riscos e impactos sejam desencadeados a partir de crises geradas por incidentes, acidentes ou severos danos ambientais, inaceitáveis. Nesses casos, tais eventos devem ser usados como indicadores de riscos onde, evidentemente, o resultado da avaliação PxS será um valor acima do Limiar de Aceitabilidade. Em situações de crise, todo o processo pode gravitar na direção do fator desencadeante limitando a visão sistêmica da gestão de riscos e impactos, negligenciando, por exemplo, a ponderação de outros fatores que não tenham sido expostos, o que deve ser evitado. Na inexistência de crise, pode ser usado como indicador para a calibragem do limiar de aceitabilidade um fator de risco característico do ambiente dado, que seja facilmente reconhecido como aceitável pela equipe de planejamento e, portanto, fácil de 
avaliar nos seus parâmetros $\mathrm{P}$ e $\mathrm{S}$, cujo produto, $\mathrm{PxS}$, será menor ou igual ao Limiar de Aceitabilidade. Deve-se reconhecer que o grau de incertezas para quantificar impactos ambientais é alto, assim como as metas a atingir podem sofrer reavaliações durante o processo de melhoria contínua e aprendizagem (Kates et al, 2001).

Uma vez definida e acertada a metodologia, os indicadores, e o Limiar de Aceitabilidade, o processo LAR+LAC de avaliação de riscos e danos poderá ser executado para cada atividade ou roteiro, ou seja, de acordo com escopo a ser definido. É importante compreender que a quantificação deste processo parte da percepção de riscos dos avaliadores que estará determinada pela experiência prévia e fatores externos, tais como influências culturais, mídia e até mitos locais, dado que este processo raramente pode ser baseado em estatísticas. 0 inventário prévio de perigos e ameaças potenciais será o ponto de partida da avaliação de riscos. Reconhecidos os perigos e ameaças potenciais, os danos possíveis deverão ser listados e avaliados segundo sua probabilidade e severidade como se exemplifica na Figura 2. Tal processo deverá ser documentado para permitir as revisões subsequentes.

No caso de perigos para o ambiente, o processo é análogo. Neste caso, por exemplo, podem ser indicados como fatores de atenção ou de vulnerabilidade ambiental a danos aqueles listados no Quadro 2. A existência dos mesmos não pressupõe necessariamente que resultem impactados pela visitação. Para tal, os riscos de danos deverão ser qualificados e quantificados, avaliando a probabilidade e severidade de, por exemplo, atropelamentos de fauna, incêndios, afugentamentos de fauna, extração de flora, novos atalhos, quebra de espeleotemas, extração de conchas, etc. É importante ponderar que, reconhecendo o sistema socioecológico como um sistema complexo, a correlação entre causas e efeitos pode ser difícil de predizer e quantificar (McCool, 2009). Isto é relevante, em particular, na previsão e avaliação de impactos da visitação na fauna e seu comportamento, pois é reconhecido que espécies podem se habituar a perturbações humanas (Lindsay, Craig, \& Low, 2008). Logo padrões que possam servir para sistematizar observações sobre declínio de populações se tornarão relevantes na medida em que tais evidências possam ser monitoradas no tempo.

0 processo documentado na Figura 3 é cíclico. Uma vez identificados riscos cuja avaliação esteja acima do limiar de aceitabilidade, opções de tratamento deverão ser propostas, indicados como (I) na coluna 8, na mesma Figura. No ciclo seguinte estas sugestões de tratamento (coluna 8) deverão ser implementadas como procedimentos operacionais indicados na coluna 5 como (II), o que poderá diminuir a probabilidade (como no exemplo das colunas 5, linhas 1 e 6 ou a severidade dos danos, como na coluna 6,linha 8), indicadas como (III). Dessa maneira, os riscos tratados poderão ser enquadrados dentro do limiar de aceitabilidade.

Os locais de atenção do SGSI deverão ser mapeados e sobrepostos ao zoneamento da UC, como ilustrado na Figura 4. Esta ação auxiliará a tomada de decisão, que estará assim subsidiada pelas definições de uso e grau de intervenção possíveis, indicados nos Planos de Manejo. Por exemplo, nessa Figura 4 aparecem em destaque o local $\mathrm{O}_{1}$ até o $\mathrm{O}_{6}$ que correspondem a danos ou ameaças 
listados na tabela de avaliação de riscos onde se indica o monitoramento permanente como opção de tratamento ou alternativa de controle operacional existente. A avaliação, ao levar em consideração o zoneamento interno de UCs, deve prever que em locais onde o zoneamento é mais restritivo, o nível de perturbação e ou intervenção no ambiente deve ser menor. Ou seja, quanto mais restritivo, maior a severidade das alterações e impactos avaliados.

Figura 3 - Exemplo de fragmento de tabela dinâmica de identificação e avaliação de riscos por roteiro ou atividade indicando o fluxo de tratamento com vista a ajustar certos riscos para dentro do limiar de aceitabilidade

\begin{tabular}{|c|c|c|c|c|c|c|c|}
\hline \multicolumn{6}{|c|}{$\begin{array}{l}\text { Planilha de Identificação e Avaliação de Riscos } \\
\text { Produto: Travessia da Serra Azul (caminhada com acampamento e pernoite) }\end{array}$} & \multirow{2}{*}{\multicolumn{2}{|c|}{ Organizado por: }} \\
\hline \multicolumn{4}{|c|}{$\begin{array}{ll}\text { Rata da Revisão: } 12 \text { de Dezembro de } 2017 & \text { Realizado por: GT-SGSI }\end{array}$} & \multirow{2}{*}{$\begin{array}{l}\text { Aprovado por: } \\
\text { Probabilidade } \\
\text { (P) }\end{array}$} & & & \\
\hline $\begin{array}{l}\text { Etapas da } \\
\text { Atividade } \\
\text { (Zoneamento } \\
\text { da UC) }\end{array}$ & $\begin{array}{l}\text { Perigos, ameaças ou } \\
\text { fatores de atenção } \\
\text { ambiental } \\
\text { georreferenciados }\end{array}$ & Danos & $\begin{array}{l}\text { Controle Operacional } \\
\text { Existente }\end{array}$ & & $\begin{array}{l}\text { Severidade } \\
\text { (S) }\end{array}$ & $\begin{array}{l}\text { Análise do } \\
\text { Risco } \\
\text { (PxS) }\end{array}$ & Opções de Tratamento \\
\hline $\begin{array}{l}\text { Acesso de } \\
\text { carro até } \\
\text { estacionamen } \\
\text { to } \\
\text { (Zona de Uso } \\
\text { Intensivo). }\end{array}$ & $\begin{array}{l}\text { Passagem de animais } \\
\text { no ponto } \mathrm{O}_{1} \text { do mapa. }\end{array}$ & Atropelamento & $\begin{array}{l}\text { Restrição de horário de } \\
\text { acesso de veículos. } \\
\text { (II) }\end{array}$ & (III) & 5 & 10 & $\begin{array}{l}\text { Colocação de placas de } \\
\text { alerta. Monitoramento } \\
\text { e registros no ponto } \mathrm{O}_{1} \\
\text { do mapa. }\end{array}$ \\
\hline \multirow{2}{*}{$\begin{array}{l}\text { Trecho de vale } \\
\text { (Zona de Uso } \\
\text { Extensivo). }\end{array}$} & $\begin{array}{l}\text { Longo trecho de } \\
\text { exposição ao sol forte }\end{array}$ & $\begin{array}{l}\text { Insolação e } \\
\text { desidratação } \\
\text { moderada. }\end{array}$ & $\begin{array}{l}\text { Informação prévia ao usu } \\
\text { sobre uso de protetor sol } \\
\text { boné e água. }\end{array}$ & 1 & & 2 & \\
\hline & $\begin{array}{l}\text { Trecho de várzea } \\
\text { sujeito a alagamento } \\
\text { na regiâa } \mathrm{O}_{2} \text { do mapa. }\end{array}$ & $\begin{array}{l}\text { Alargamento da } \\
\text { trilha }\end{array}$ & $\begin{array}{l}\text { Monitoramento das } \\
\text { condições climáticas e da } \\
\text { largura da trilha < } 3 \text { metros. } \\
\text { Orientaçã̃o ao usuário. }\end{array}$ & 1 & 3 & 3 & \\
\hline $\begin{array}{l}\text { Travessia de } \\
\text { curso d'água } \\
\text { (Zona de Uso } \\
\text { Extensivo). }\end{array}$ & $\begin{array}{l}\text { Perigo de afogamento } \\
\text { no ponto } \mathrm{O}_{3} \text { do mapa }\end{array}$ & Morte & $\begin{array}{l}\text { Monitoramento das } \\
\text { condições climáticas e } \\
\text { suspensão da atividade em } \\
\text { caso de chuvas. }\end{array}$ & 1 & 5 & 5 & \\
\hline \multirow{4}{*}{$\begin{array}{l}\text { Trecho de } \\
\text { Serra } \\
\text { (Zona } \\
\text { Primitiva) }\end{array}$} & Nidificação de aves & Afugentamento & $\begin{array}{l}\text { Orientação sobre silêncio no } \\
\text { trecho }\end{array}$ & 1 & 5 & 5 & (I) \\
\hline & $\begin{array}{l}\text { Atalhos novos na trilha } \\
\text { no ponto } \mathrm{O}_{4} \text { do mapa }\end{array}$ & Erosão & & 3 & 4 & 12 & $\begin{array}{l}\text { Colocação de } \\
\text { sinalização. } \\
\text { Monitoramento }\end{array}$ \\
\hline & \multirow{2}{*}{$\begin{array}{l}\text { Transposição de } \\
\text { afloramentos rochosos } \\
\text { em trechos } \\
\text { escorregadios }\end{array}$} & Escoriações & (II) & 2 & 2 & & (I) \\
\hline & & $\begin{array}{l}\text { Traumas na } \\
\text { cabeça }\end{array}$ & & 2 & (III) 5 & 10 & $\begin{array}{l}\text { Introdução de uso } \\
\text { obrigatório de } \\
\text { capacete. }\end{array}$ \\
\hline $\begin{array}{l}\text { Acampamento } \\
\text { (Zona } \\
\text { Primitiva) }\end{array}$ & $\begin{array}{l}\text { Fogueiras no ponto } \mathrm{O}_{5} \\
\text { do mapa }\end{array}$ & Incêndio & $\begin{array}{l}\text { Proibição de fogueiras e } \\
\text { orientação de uso de } \\
\text { fogareiro. }\end{array}$ & & 5 & & \\
\hline
\end{tabular}

O processo de avaliação de riscos terá que ser complementado com a implementação sistemática de registros de incidentes, acidentes, danos ou não conformidades a partir da criação de documentos padronizados para tal, conforme exemplo exposto na Figura 5. Neste tipo de registro deve constar (ABNT, 2014): atividade, dia, local e hora exatos, breve descrição do evento, pessoas envolvidas, causas prováveis, tratamento no local, consequências desse tratamento e quem é o responsável por tais informações. 0 mesmo deverá ser submetido a um processo de revisão indicando ações preventivas ou corretivas e quem aprova tal registro. Tais registros serão peças-chave na alimentação do processo contínuo de monitoramento, avaliação de impactos, sendo fundamentais também para avaliar a resposta a emergências que deverá necessariamente constar no SGSI. 
Figura 4 - Exemplo ilustrativo do mapeamento e sobreposição da setorização do SGSI para um roteiro e o zoneamento de uma UC seguindo a avaliação de riscos na Figura 3

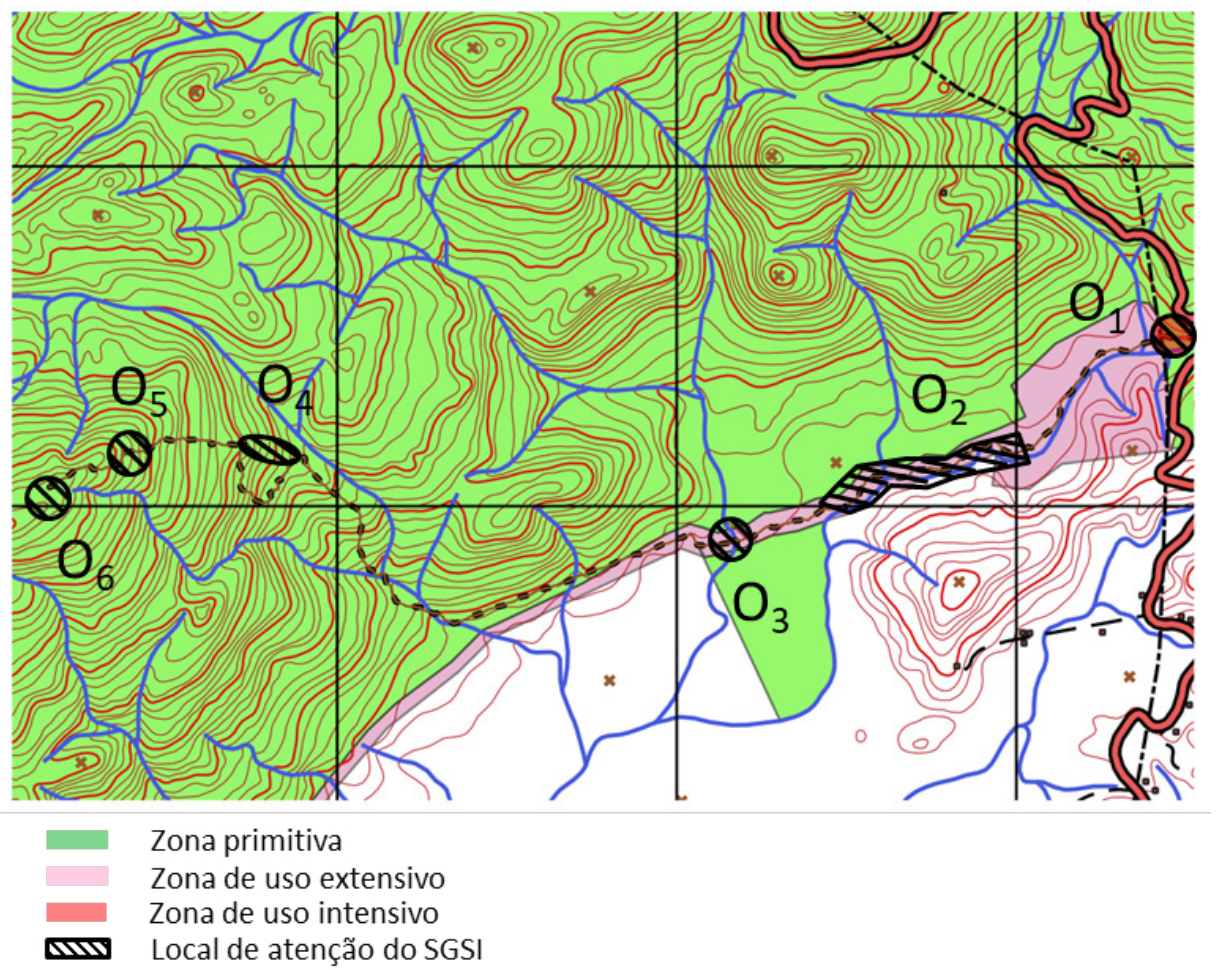

Fonte - Dados da pesquisa.

São estes registros que permitirão quantificar e qualificar o processo de gestão de riscos. No caso de potenciais danos ao ambiente, resulta importante predefinir indicadores que facilitem este processo. Por exemplo, uma vez definido no inventário prévio que na atividade dada devam ser avaliados os riscos de aparecimento de novos atalhos na trilha ou extração de flora, estes tipos de evidência passam a ser consideradas danos relevantes a registrar e avaliar, e eventualmente tratar usando o referencial metodológico disponível (Hesselbarth, Vachowski, \& Davie, 2007).

Figura 5 - Exemplo de planilha de registro de danos, incidentes ou acidentes e avaliações

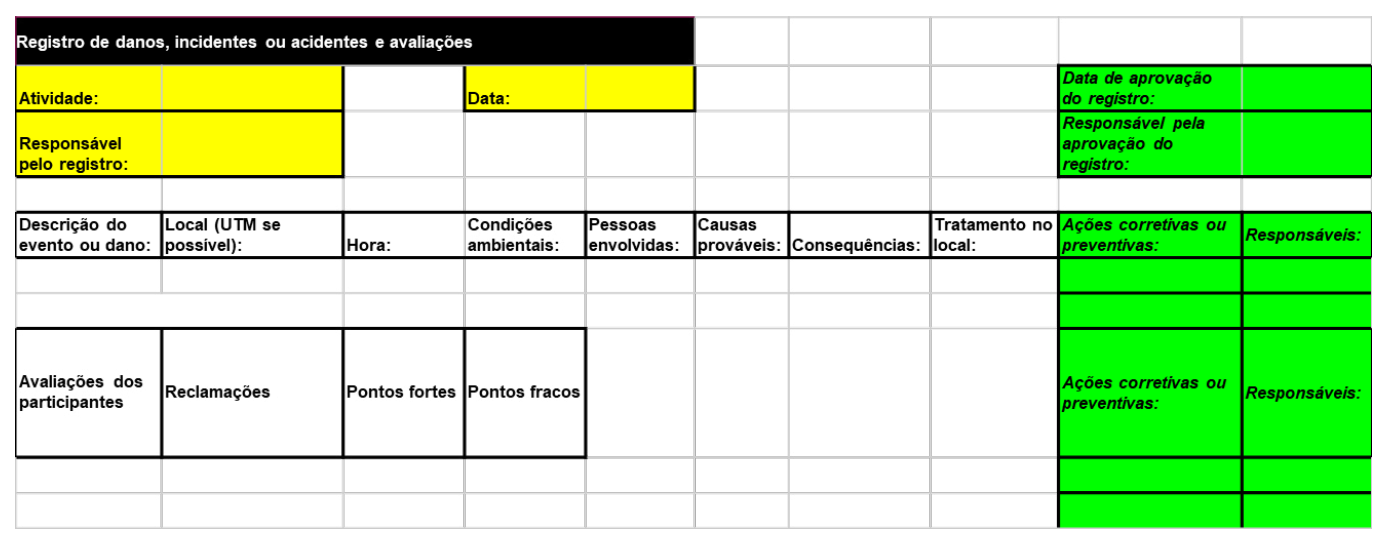

Fonte - Dados da Pesquisa 
Dada a sistemática carência de pessoal capacitado exclusivamente para monitoramento e avaliação de impactos e riscos da visitação, considera-se que tais atividades possam ser atribuições do coletivo de monitores credenciados e treinados dentro do SGSI para orientar e conduzir a visitação. É possível posicionar também o visitante autônomo, que deve zelar pelos próprios padrões de precaução, como fiscalizador de impactos, envolvendo-o na metodologia de registros. Além de uma fonte relevante de dados, o empoderamento do visitante com sua ativa participação neste processo serve de mecanismo indutor de boas práticas, motivando e valorizando seu comportamento idôneo. Um exemplo de ficha de registros está ilustrado na Figura 5. Recomenda-se que este tipo de documento, complementado com o inventário de riscos e indicadores, possa ser compartilhado e preenchido digitalmente de forma remota e, em tempo real, usando as ferramentas virtuais de compartilhamento de planilhas e aparelhos de celular.

Durante este processo, novos tipos de perigos e danos podem aparecer sem haver sido ponderados no inventário preliminar e assim, uma vez registrados e qualificados, poderão ser oportunamente considerados e avaliados na revisão subsequente do SGSI. Incidentes, acidentes e danos são eventos que devem exigir a reavaliação dos riscos.

Por sua vez, quanto à indicação de ações corretivas e novos Procedimentos Operacionais, considera-se como de possível atribuição de Grupos de Apoio Técnico ou Câmaras Técnicas (SMA, 2016), que dão suporte interdisciplinar aos Conselhos Consultivos das UCs como orienta o Decreto Estadual № 60.302 (São Paulo, 2014), que dispõe sobre a criação e diretrizes de funcionamento dos Conselhos Consultivos das Unidades de Conservação de Proteção Integral do Estado de São Paulo. Nestes espaços colaborativos, com desejável cogestão flexível, poderão ser construídas as melhores alternativas de tratamento que assim poderão ser mais facilmente apropriadas por todos os atores, respeitando as visões diferentes e potencialmente conflitantes (Passold, Magro, \& Couto, 2004). Este processo é necessariamente cíclico e em muitos casos a evolução acontece a partir de tentativa-e-erro e do aprendizado coletivo, que permite o compartilhamento de responsabilidades (Folke et al. 2002). No Quadro 5 é exposto um exemplo de possíveis etapas da estruturação do SGSI, associadas às fases cíclicas ilustradas na Figura 1.

Quadro 5 - Exemplos de etapas do Planejamento do SGSI

\begin{tabular}{|l|l|l|}
\hline \multicolumn{1}{|c|}{ Etapas do planejamento do SGSI } & Fase do ciclo de gestão \\
\hline 1 & $\begin{array}{l}\text { Estruturação de Grupo de Trabalho e/ou } \\
\text { Câmara Técnica para o SGSI em parceria com } \\
\text { partes interessadas }\end{array}$ & \\
\hline 2 & Definição de metas e escopos do SGSI & $\begin{array}{l}\text { Definição do escopo e dos indicadores } \\
\text { e limiares de aceitabilidade para o }\end{array}$ \\
\hline 3 & $\begin{array}{l}\text { Construção de consensos sobre procedimentos } \\
\text { de avaliação, indicadores e ferramentas de } \\
\text { registros e limites de aceitabilidade. }\end{array}$ & \\
\hline
\end{tabular}

continua... 


\section{Quadro 5 - Continuação}

\begin{tabular}{|l|l|l|}
\hline 4 & $\begin{array}{l}\text { Distribuição de tarefas para mapeamento, } \\
\text { inventário e primeiro ciclo de avaliação de } \\
\text { riscos e impactos em roteiros e/ou atividades }\end{array}$ & \\
\hline 5 & $\begin{array}{l}\text { Discussão de alternativas de tratamento a } \\
\text { riscos e impactos não aceitáveis. }\end{array}$ & $\begin{array}{l}\text { Avaliação de riscos e proposição de } \\
\text { alternativas de tratamento }\end{array}$ \\
\hline 6 & $\begin{array}{l}\text { Estruturação e testes de mecanismos de } \\
\text { respostas a emergências }\end{array}$ & $\begin{array}{l}\text { Implementação de Procedimentos } \\
\text { Operacionais para se ajustar aos } \\
\text { LAR+LAC }\end{array}$ \\
\hline 7 & $\begin{array}{l}\text { Implementação de procedimentos } \\
\text { operacionais. }\end{array}$ & $\begin{array}{l}\text { Monitoramento contínuo de resultados } \\
\text { com sistema de registros }\end{array}$ \\
\hline 8 & $\begin{array}{l}\text { Implementação de procedimentos de } \\
\text { monitoramento e registros de danos, } \\
\text { incidentes e acidentes. }\end{array}$ & $\begin{array}{l}\text { Análise periódica e consideração de } \\
\text { ações corretivas }\end{array}$ \\
\hline 9 & $\begin{array}{l}\text { Avaliação do processo e revisão de não } \\
\text { conformidades. }\end{array}$ \\
\hline
\end{tabular}

\section{CONSIDERAÇÕES FINAIS}

Frente aos problemas e desafios levantados a partir de experiências vivenciadas junto a UCs do Estado de São Paulo, considera-se que a busca por processos integradores e que permeiem toda a estrutura de visitação de áreas protegidas possa ser um avanço. Neste sentido, entende-se que a proposta exposta, pela sua simplicidade e replicabilidade, pode se tornar ferramenta viável para o adequado monitoramento e gestão de impactos e segurança para a visitação dessas áreas. A implementação do processo LAR+LAC permite integrar a gestão de segurança dos participantes e do ambiente dentro do mesmo marco adaptável do SGSI. Parcerias entre gestores, condutores e visitantes devem contribuir à resiliência do SGSI sempre que o mesmo se institucionalize a partir de processos participativos, onde inevitavelmente aflorarão conflitos, mas onde consensos possam ser construídos. A apropriação dos métodos propostos depende fortemente da efetivação destes espaços, tais como grupos de trabalho, e de seu empoderamento, onde todos os atores possam contribuir a partir de suas visões, experiências e competências ao processo de cogestão com transparência e compreendendo suas responsabilidades e funções (McCool, 2009). Este elemento é crítico em sistemas onde recursos humanos, de capital e custeio são escassos, inibindo a eficácia de processos verticais top-down.

A aplicação deste modelo facilita a gestão da visitação, uma vez que aborda, num único sistema, duas das dimensões do gerenciamento de atividades de ecoturismo e turismo de aventura: os riscos aos visitantes e os impactos da visitação. Estes são trabalhados e tratados comumente de forma separada, o que demanda o empenho de recursos e tempo para execução dessas importantes frentes, muitas vezes indisponíveis. Apesar do planejamento sugerido se basear em documentos e registros, o mesmo deve ser compreendido como um processo sistemático de aprendizagem e reflexão que integre, de maneira permanente: pessoas, recursos e procedimentos (incluindo avaliações e auditorias) para atingir metas definidas, compreendidas e almejadas por todos os atores. 


\section{REFERÊNCIAS}

ABETA - Associação Brasileira de Empresas de Ecoturismo e Turismo de Aventura (2009) Manual de Boas Práticas de Sistema de Gestão da Segurança - ABETA e Ministério do Turismo - Belo Horizonte - Série Aventura Segura.

ABNT - Associação Brasileira de Normas Técnicas. (2014) Turismo de Aventura - Sistema de Gestão de segurança - Requisitos (NBR ISO No. 21101:2014). Disponível em: https://www.abntcatalogo.com.br/norma.aspx?ID=326146. Acesso em: 10 Fev. 2020.

ABNT - Associação Brasileira de Normas Técnicas. (2015) Turismo de Aventura Líderes - Competência de pessoal (NBR No. 15285:2015). Disponível em: https:// www.abntcatalogo.com.br/norma.aspx?ID=333645. Acesso em: 10 Fev. 2020.

ABNT - Associação Brasileira de Normas Técnicas. (2019) Turismo de Aventura - Boas práticas de sustentabilidade - Requisitos e recomendações (NBR ISO No. 20611:2019). Disponível em: https://www.abntcatalogo.com.br/norma.aspx?ID=423432. Acesso em: 10 Fev. 2020.

Bentley, T. A. \& Page, S. J. (2001). Scoping the extent of adventure tourism accidents. Annals of Tourism Research 28(1): 705-726. DOI: 10.1016/S0160-7383(00)00058-X

Bentley, T. A. \& Page, S. J. (2008). A decade of injury monitoring in the New Zealand adventure tourism sector: A summary risk analysis. Tourism Management 29(5): 857-869. DOI: 10.1016/j.tourman.2007.10.003

Bentley, T. A.; Page, S. J. \& Cater, C. I. (2010). Adventure and ecotourism safety in Queensland: Operator experiences and practice. Tourism Management 31(5): 563-571. DOI: 10.1016/j.tourman.2009.03.006

Brasil (1990). Código de Defensa do Consumidor. Lei no 8.078:1990. Disponível em: http:// www.planalto.gov.br/ccivil_03/leis/l8078.htm. Acesso em: 17 Nov. 2019.

Brasil (2000). Institui o Sistema Nacional de Unidades de Conservação da Natureza e dá outras providências. Lei no 9.985:2000. Disponível em: http://www.planalto.gov.br/ ccivil_03/leis/19985.htm. Acesso em: 17 Nov. 2019

Cassiano, A. M.; da Silva, D. S.; Severian, B. A. \& Lopez-Richard, V. (2016). Desafíos de la capacitación y licenciamiento de los guías de Unidades de Conservación. Estudios y Perspectivas en Turismo 25(4): 483- 501. https://www.estudiosenturismo.com.ar/ $\mathrm{PDF} / \mathrm{V} 25 / \mathrm{N} 04 / \mathrm{v} 25 \mathrm{n} 4 \mathrm{a} 05 . \mathrm{pdf}$

Cater, C. I. (2006). Playing with risk? participant perceptions of risk and management implications in adventure tourism. Tourism Management 27(2): 317-325. DOI: 10.1016/j.tourman.2004.10.005

Cole, D. N. \& Stankey, G. H. (1997). Historical Development of Limits of Acceptable Change: Conceptual Clarifications and Possible Extensions. Disponível em: https://www. fs.fed.us/rm/pubs_int/int_gtr371/int_gtr371_005_009.pdf. Acesso em: 17 Nov. 2019

EMBRATUR. (1994). Diretrizes para uma política nacional de ecoturismo. Coordenação de S. Magalhães Barros e D. H. de La Penha. Brasilia: EMBRATUR. Disponível em: http:// www.ecobrasil.eco.br/3-secao-geral/categoria-projetos/977-diretrizes-da-politicanacional-de-ecoturismo. Acesso em: 17 Nov. 2019.

Farrell, T. A. \& Marion, J. L. (2002). The Protected Area Visitor Impact Management (PAVIM) Framework: A Simplified Process for Making Management Decisions. Journal of Sustainable Tourism 10(1): 31-5. DOI: 10.1080/09669580208667151

Folke, C.; Carpenter, S.; Elmqvist, T.; Gunderson, L.; Holling, C. S. \& Walker, B. (2002). Resilience and Sustainable Development: Building Adaptive Capacity in a World of 
Transformations. AMBIO: A Journal of the Human Environment 31(5):437-440. DOI: 10.1579/0044-7447-31.5.437

Galvão de Sousa Dantas, N.; de Sousa Melo, R. (2008). 0 método de análise SWOT como ferramenta para promover o diagnóstico turístico de um local: o caso do município de Itabaiana / PB. Caderno Virtual de Turismo 8(1): 118-130. http://www.ivt.coppe.ufrj.br/ caderno/index.php/caderno/article/view/272

Garrod, B. \& Fyall, A. (1998). Beyond the rhetoric of sustainable tourism? Tourism Management 19(3): 199-212. DOI: 10.1016/S0261-5177(98)00013-2

Hesselbarth, W.; Vachowski, B.; Davie, M. A. (2007). Trail Construction and Maintenance Notebook. United States Department of Agriculture Forest Service Technology \& Development Program. Disponível em: https://www.fs.fed.us/t-d/pubs/htmlpubs/ htm07232806/toc.htm. Acesso em: 17 Nov. 2019.

IBAMA. (2002). Roteiro Metodológico de Planejamento: Parque Nacional, Reserva Biológica, Estação Ecológica. IBAMA - Instituto Brasileiro do Meio Ambiente e Dos Recursos Naturais Renováveis, Brasília-DF. Disponível em: http://ava.icmbio.gov.br/mod/data/ view.php?d=17\&rid=2634. Acesso em: 17 Nov. 2019.

ICMBio. (2011). Roteiro Metodológico para Manejo de Impactos da Visitação, com Enfoque na Experiência do Visitante e na Proteção dos Recursos Naturais e Culturais. ICMBio Instituto Chico Mendes de Conservação da Biodiversidade, Brasília-DF. Disponível em: http://www.icmbio.gov.br/portal/images/stories/comunicacao/roteiro_impacto.pdf

ICMBio. (2018). Roteiro metodológico para elaboração e revisão de planos de manejo das unidades de conservação federais. ICMBio - Instituto Chico Mendes de Conservação da Biodiversidade, Brasília-DF. Disponível em: https://www.icmbio.gov.br/portal/ images/stories/comunicacao/downloads/roteiro_metodologico_elaboracao_revisao_ plano_manejo_ucs.pdf. Acesso em: 17 Nov. 2019.

Kates, R. W.; Clark, W. C.; Corell, R.; Hall, J. M.; Jaeger, C. C.; Lowe, I.; McCarthy, J. J.; Schellnhuber, H. J.; Bolin, B.; Dickson, N. M.; Faucheux, S.; Gallopin, G. C.; Grübler, A.; Huntley, B.; Jäger, J.; Jodha, N. S.; Kasperson, R. E.; Mabogunje, A.; Matson, P.; Mooney, H.; Moore III, B.; O’Riordan, T. \& Svedin, U. (2001). Sustainability science. Science 292: 641-642. DOI: 10.1126/science.1059386

Lindsay, K.; Craig, J. \& Low, M. (2008). Tourism and conservation: The effects of track proximity on avian reproductive success and nest selection in an open sanctuary. Tourism Management 29(4): 730-739. DOI: 10.1016/j.tourman.2007.08.001

Lobo, H. A. S. (2015). Caracterização e tendências de gestão dos impactos negativos e positivos do espeleoturismo. Revista Brasileira de Pesquisa em Turismo 9(2): 321-341. DOI: 10.7784 /rbtur.v9i2.842

Lopez-Richard, V. \& Chinaglia, C. (2004). Turismo de Aventura: conceitos e paradigmas fundamentais. Turismo em Análise 15(2): 199-215. DOI: 10.11606/issn.1984-4867. v15i2p199-215

Lopez-Richard, V.; Alamino, W. \& Simões, M. (2007). Gerenciamento de Riscos em Programas de Aventura. Turismo em Análise 18(1): 94-108. DOI: 10.11606/issn.1984-4867. v18i1p94-108

McCool, S. F. \& Cole, D. N. (1997).. Experiencing limits of acceptable change: some thoughts after a decade of implementation, Disponível em: https://www.fs.fed.us/rm/pubs_int/ int_gtr371/int_gtr371_072_078.pdf. Acesso em: 17 Nov. 2019.

McCool, S. F. (2009). Constructing partnerships for protected area tourism planning in an era of change and messiness. Journal of Sustainable Tourism 17(2): 133-148. DOI $10.1080 / 09669580802495733$ 
Ministério do Turismo. (2010). Ecoturismo: orientações básicas. Ministério do Turismo, Secretaria Nacional de Políticas de Turismo. 2. ed. Brasília: Ministério do Turismo. Disponível em: http://antigo.turismo.gov.br/sites/default/turismo/o_ministerio/ publicacoes/downloads_publicacoes/Ecoturismo_Versxo_Final_IMPRESSxO_.pdf. Acesso em: 17 Nov. 2019.

Ministério do Turismo. (2006). Turismo de Aventura: orientações básicas. Ministério do Turismo, Secretaria Nacional de Políticas de Turismo. Brasília: Ministério do Turismo. Disponível em: http://www.dominiopublico.gov.br/download/texto/tu000018.pdf. Acesso em: 17 Nov. 2019.

Nyaupane, G. P. \& Poudel, S. (2011). Linkages among Biodiversity, Livelihood, and Tourism. Annals of Tourism Research 38(4): 1344-1366. DOI: 10.1016/j.annals.2011.03.006

Passold, A. J.; Magro, T. C.; Couto, H. T. Z. (2004). Comparing Indicators Effectiveness for Monitoring Visitor Impact in Intervales State Park, Brazil: Park Ranger-Measured Versus Specialist-Measured Experience. The Second International Conference on Monitoring and Management of Visitor Flows in Recreational and Protected Areas, Rovaniemi, Finland, Jun. 2004. Disponível em: http://www.metla.fi/julkaisut/ workingpapers/2004/mwp002-08.pdf. DOI: Acesso em: 17 Nov. 2019.

Reid, R. A.; Koljonen, E. L. \& Buell, J. B. (1999). The Deming cycle provides a framework for managing environmentally responsible process improvements. Quality Engineering 12(2): 199-209. DOI: 10.1080/08982119908962577

São Paulo (2014). Decreto № 60.302, de 27 de março de 2014, Institui o sistema de Gestão de Áreas Protegidas no Estado de São Paulo. Disponível em: https://www.al.sp.gov.br/ repositorio/legislacao/decreto/2014/decreto-60302-27.03.2014.html. Acesso em: 17 Nov. 2019.

Silveira, D. T. \& Córdova, F. P. (2009) A Pesquisa Científica em Métodos de Pesquisa, Porto Alegre: Editora da UFRGS: 31-42.

SMA - Secretaria do Meio Ambiente. (2010). Manual de Monitoramento e Gestão dos Impactos da Visitação em Unidades de Conservação. Secretaria do Meio Ambiente, São Paulo. Disponível em: http://arquivo.ambiente.sp.gov.br/publicacoes/2016/12/ manualadeamonitoramentoaeagestoadosaimpactosadaavi.pdf. Acesso em: 17 Nov. 2019.

SMA - Secretaria do Meio Ambiente. (2008). Resolução SMA n059, de 27 de agosto de 2008. Secretaria do Meio Ambiente, São Paulo. Disponível em: http://www.mpsp. $\mathrm{mp} . \mathrm{br} /$ portal/page/portal/cao_urbanismo_e_meio_ambiente/legislacao/leg_estadual/ leg_est_resolucoes/Resolucao-SMA-59-2008.pdf. Acesso em: 17 Nov. 2019.

SMA - Secretaria do Meio Ambiente. (2008a). Plano de Manejo do Parque Estadual da Serra do Mar. Instituto Florestal, Secretaria do Meio Ambiente, São Paulo. http://fflorestal. sp.gov.br/pagina-inicial/planos-de-manejo/planos-de-manejo-planos-concluidos/ plano-de-manejo-pe-serra-do-mar/. Acesso em: 17 Nov. 2019.

SMA - Secretaria do Meio Ambiente. (2008b). Plano de Manejo Parque Estadual Carlos Botelho. Instituto Florestal, Secretaria do Meio Ambiente, São Paulo http://fflorestal. sp.gov.br/pagina-inicial/planos-de-manejo/planos-de-manejo-planos-concluidos/ plano-de-manejo-pe-carlos-botelho/. Acesso em: 17 Nov. 2019.

SMA - Secretaria do Meio Ambiente. (2008c). Plano de Manejo Parque Estadual Intervales, Instituto Florestal, Secretaria do Meio Ambiente, São Paulo http://fflorestal.sp.gov.br/ pagina-inicial/planos-de-manejo/planos-de-manejo-planos-concluidos/plano-demanejo-pe-intervales/. Acesso em: 17 Nov. 2019.

SMA - Secretaria do Meio Ambiente. (2016). Resolução SMA № 54, de 05 de junho de 2016. Dispõe sobre os procedimentos para a instituição dos Conselhos Consultivos das unidades de conservação administradas pela Fundação para a Conservação e a Produção Florestal do Estado de São Paulo. Secretaria do Meio Ambiente, São Paulo. Disponível 
em: https://www.infraestruturameioambiente.sp.gov.br/legislacao/2016/06/ resolucao-sma-54-2016/. Acesso em: 17 Nov. 2019.

Stankey, G. H.; Cole, D. N.; Lucas, R. C.; Petersen, M. E. \& Frissell, S. S. (1985). The Limits of Acceptable Change (LAC) system for wilderness planning. General Technical Report INT. USDA. Forest Service, Ogden, 176: 1-37. Disponível em: https://www.fs.usda.gov/ Internet/FSE_DOCUMENTS/stelprdb5346594.pdf. Acesso em: 17 Nov. 2019.

Weaver, D. B; Lawton, L. J. (2017). A new visitation paradigm for protected areas. Tourism Management 60: 140-146. DOI: 10.1016/j.tourman.2016.11.018

Williams, P. \& Soutar, G. N. (2009). Value, Satisfaction and Behavioral Intentions in an Adventure Tourism Context. Annals of Tourism Research 36(3): 413-438. DOI: 10.1016/ j.annals.2009.02.002

Williams, P. W. \& Ponsfor, I. F. (2009). Confronting tourism's environmental paradox: Transitioning for sustainable tourism. Futures 41(6): 396-404. DOI: 10.1016/ j.futures.2008.11.019

Yin, R. K. (2001). Estudo de caso: planejamento e métodos. Porto Alegre: Brookman.

Recebido em: 06/09/2020

Aprovado em: 01/12/2020

\section{CONTRIBUIÇÃo}

Victor Lopez-Richard: Definição do problema de pesquisa e objetivos, desenvolvimento da proposição teórica, realização da revisão bibliográfica e fundamentação teórica, escolha dos procedimentos metodológicos, coleta e análise de dados, elaboração de tabelas, gráficos e figuras, revisão crítica e redação do manuscrito e adequação do manuscrito às normas da RTA.

Andréia Márcia Cassiano: Definição do problema de pesquisa e objetivos, escolha dos procedimentos metodológicos, análise de dados e revisão crítica e redação do manuscrito.

Rodrigo Jose Silva Aguiar: Definição do problema de pesquisa e objetivos, desenvolvimento da proposição teórica, elaboração de tabelas, gráficos e figuras e revisão crítica e redação do manuscrito. 